Results For 72 children (31 girls, 41 boys), 91 decision-making meetings were organised. We identified 27.7\% (20/72) disagreements or conflicts: 4 simple disagreements, 12 continuing disagreements and 4 conflicts. Five children had acute disease and 15 children had chronic disease. Source of disagreements was continuing LST in 19 cases (families wanted to continue aggressive treatment). In 1 case, the family wanted to stop treatments despite medical opinion (refusal of tracheotomy). Consequences of theses disagreements were continuation of treatments despite LST decisions in 12 cases. For 3 cases a compromise solution was found.

Conclusion Disagreements are frequent in decisions to forgo LST $(27,7 \%)$ and most of the child undergo treatments that are medically futile.

\section{PO-0319 IS THERE SUFFERING IN CHILDREN FOUR YEARS AFTER A PICU ADMISSION?}

${ }^{1} \mathrm{~W}$ De Weerd, ${ }^{2} \mathrm{M}$ Brouwer, ${ }^{1} \mathrm{PJJ}$ Sauer, ${ }^{2} \mathrm{ELM}$ Mackelberghe. ${ }^{1}$ Pediatric, Beatrix Children's Hospital/University Medical Center Groningen, Groningen, Netherlands; ${ }^{2}$ Health Sciences/ Medical Ethics, University Medical Center Groningen, Groningen, Netherlands

10.1136/archdischild-2014-307384.968

Background and aims In a previous study on suffering of children during admission to a paediatric intensive care unit (PICU), we found that parents described suffering of their child mainly in relation to physical symptoms. In this study we evaluated if these children still have signs of suffering four years after the PICU admission and if the symptoms of suffering, as perceived by the parents, are different compared to the PICU period.

Methods A structured audio taped interview with 15 parents of children four years after admission to a 20 bed level III PICU of a university teaching hospital to assess whether their child perceived to suffer and to identify perceived aspects of suffering.

Results About $50 \%$ of the parents experienced 4 years after PICU admission suffering in their child. Parents of 8 children did not perceive suffering in their child. Parents indicated that the suffering during the PICU admission was due to physical and psychosocial factors. Psychosocial factors were related to the disease causing the admission to the PICU, the treatment and the hospital stay. Four years later the signs of suffering are related to communication, physical and mental retardation and being different from mates.

Conclusions A child's admission to a PICU and its suffering not only cause suffering in the child during admission, but often suffering is still present four years after admission. Caregivers in paediatrics need to be aware of these perceived symptoms. In long-term follow up of critically ill children this phenomena needs attention.

\section{PO-0320 SUFFERING OF PARENTS FOUR YEARS AFTER PICU ADMISSION OF THEIR CHILD}

${ }^{1} \mathrm{~W}$ De Weerd, ${ }^{2} \mathrm{M}$ Brouwer, ${ }^{1} \mathrm{PJJ}$ Sauer, ${ }^{2}$ ELM Mackelberghe. ${ }^{1}$ Pediatric, Beatrix Children's Hospital/University Medical Center Groningen, Groningen, Netherlands; ${ }^{2}$ Health Sciences/ Medical Ethics, University Medical Center Groningen, Groningen, Netherlands

10.1136/archdischild-2014-307384.969

Background and aims Admission of a child to a paediatric intensive care unit (PICU) is a very stressful event for the child, but also for the parents. This might not only lead to suffering during admission, but also might have lasting effects. Little is known about the long term effects. In a previous study done during the stay of a child in a PICU we saw that a child's admission to a PICU causes suffering of parents. In this study we evaluated if there are still feelings of suffering in parents four years after PICU admission.

Methods A structured audio taped interview with 15 parents of children four years after admission of the child to a 20 bed level III PICU of a university teaching hospital to assess whether parents still have feelings of suffering and to identify aspects of suffering.

Results Four years after PICU admission about 50\% of the parents indicated that they still have feelings of suffering. Parents of 6 children didn't suffer themselves. Parents describe mainly physical and psychosocial causes for the suffering. Reasons for suffering are experiencing changes in the physical and mental situation of the child. Also, the uncertainty of the future, effects on the family and problems in the organisation of healthcare contribute to the suffering.

Conclusions A child's admission to a PICU causes long term suffering in the parents. Caregivers in paediatrics need to be aware of these phenomena and should give attention to these aspects in the follow up support.

\section{PO-0321 NONINVASIVE VENTILATION AND ALVEOLAR RECRUITMENT MANOEUVRE IMPROVE RESPIRATORY FUNCTION DURING INDUCTION OF ANAESTHESIA OF NEWBORN WITH HIGHER LEVER INTRA-ABDOMINAL PRESSURE}

${ }^{1}$ D Dmytriiev, ${ }^{1} \mathrm{~K}$ Dmytriiev, ${ }^{2} \mathrm{~K}$ Dmytriieva, ${ }^{2} \mathrm{O}$ Katilov. ${ }^{1}$ Intensive Care, Vinnitsa National Medical University, Vinnitsa, Ukraine; ${ }^{2}$ Radiology, Vinnitsa National Medical University, Vinnitsa, Ukraine

\subsection{6/archdischild-2014-307384.970}

Background Morbid obesity predisposes patients to lung collapse and hypoxemia during induction of anaesthesia. The aim of this prospective study was to determine whether noninvasive positive pressure ventilation (NPPV) improves arterial oxygenation and end-expiratory lung volume (EELV) compared with conventional preoxygenation, and whether NPPV followed by early recruitment manoeuvre (RM) after endotracheal intubation (ETI) further improves oxygenation and respiratory function compared with NPPV alone.

Methods 24 patients with higher lever intra-abdominal pressure $\left(15,2 \pm 2,4 \mathrm{~cm} \mathrm{H}_{2} \mathrm{O}\right)$ were randomised to receive $5 \mathrm{~min}$ of either conventional preoxygenation with spontaneous breathing of $100 \% \mathrm{O}_{2}(\mathrm{CON}), \mathrm{NPPV}$ (pressure support and positive endexpiratory pressure), or NPPV followed by RM (NPPV+RM). Gas exchange was measured in awake patients, at the end of preoxygenation, immediately after ETI, and 5 min after the onset of mechanical ventilation. EELV was measured immediately after ETI and $5 \mathrm{~min}$ after mechanical ventilation. The primary endpoint was arterial oxygenation $5 \mathrm{~min}$ after the onset of mechanical ventilation. Intra-abdominal pressure (IAP) was controlled by Cron Results are presented as mean \pm SD.

Results At the end of preoxygenation, $\mathrm{PaO}_{2}$ was higher in the $\mathrm{NPPV}$ and NPPV+RM groups $(382 \pm 68 \mathrm{mmHg}$ and $362 \pm 71$ $\mathrm{mmHg}$, respectively; both $\mathrm{p}<0.001)$ compared with the CON group $(297 \pm 49 \mathrm{mmHg})$ and remained higher after ETI $(234 \pm$ $90 \mathrm{mmHg}$ and $206 \pm 94 \mathrm{mmHg}$, in the NPPV and NPPV+RM groups, respectively; both $\mathrm{p}<0.01$ compared with the CON 